\title{
Hemangioblastoma Mimicking Tentorial Meningioma: Preoperative Embolization of the Meningeal Arterial Blood Supply
}

\author{
-Case Report-
}

\author{
Hitoshi TsUgU, Takeo FUKUSHIMA, Koichi IKEDA, Hidetsuna UtsunOMIYA*, \\ and Masamichi TOMONAGA
}

Departments of Neurosurgery and *Radiology, Fukuoka University School of Medicine, Fukuoka

\begin{abstract}
A 72-year-old male presented with a primary hemangioblastoma of the posterior fossa with unusual dural attachment and meningeal arterial blood supply from the external carotid artery and marginal tentorial artery. Preoperative embolization facilitated complete resection of the tumor with no resultant neurological deficit. Hemangioblastoma must be included in the differential diagnosis of tumors with dural involvement. Preoperative embolization is very useful in such tumors.
\end{abstract}

Key words: dural involvement, hemangioblastoma, meningeal arterial blood supply, preoperative embolization

\section{Introduction}

Hemangioblastomas account for $1.5 \%$ to $2.5 \%$ of all intracranial tumors and $7 \%$ to $12 \%$ of all posterior fossa tumors. ${ }^{\left.1{ }^{7}\right)}$ The posterior fossa is the preferential site $(92.6 \%)$, more frequently in the cerebellum $(80 \%)$ than in the brain stem $(7.5 \%) .{ }^{2)}$ Supratentorial, spinal cord, and orbital lesions are less common, and optic nerve ${ }^{9,10)}$ and intrasellar lesions ${ }^{14)}$ are encountered only rarely. Hemangioblastomas abut the pial surface of the cerebellum, and appear as a well-defined hypervascular mass supplied almost exclusively by cerebellar arteries: superior cerebellar artery, anterior inferior cerebellar artery, and/or posterior inferior cerebellar artery, depending on the locations. These tumors do not usually involve adjacent dura and are not normally supplied by meningeal arteries.

Dural involvement is present in up to $20 \%$ of posterior fossa hemangioblastomas, ${ }^{15)}$ but usually at postoperative recurrence. ${ }^{6,123}$ The blood supply in such cases may involve the marginal and basal tentorial arteries of the carotid siphon and meningeal

Received May 13, 1998; Accepted September 8, 1998 arteries arising from the vertebral artery and the external carotid artery. ${ }^{3-6,12,13,16-18,20)}$ We describe a case of primary hemangioblastoma with dural involvement, which is characteristic of tentorial meningioma.

\section{Case Report}

A 72-year-old male presented with dizziness which he first noticed when driving and had persisted for 2 weeks. His family history was negative for HippelLindau disease.

Neurological examination was not remarkable except for saccadic eye movement on pursuit and horizontal nystagmus on right lateral gaze. No retinal capillary hemangioma was present. $T_{1}$-weighted magnetic resonance (MR) imaging demonstrated a solid, slightly heterogeneous, isointense huge mass lesion embedded in the right cerebellum (Fig. 1A). $\mathrm{T}_{2}$-weighted $\mathrm{MR}$ imaging showed the lesion as hyperintense to gray matter, with many spotty low intensity structures within the lesion as flow-void sign (Fig. 1B). A hyperintense area surrounding the mass lesion in the cerebellar hemisphere and vermis suggested perifocal edema. The mass, abutting onto the tentorium, was enhanced intensely after 

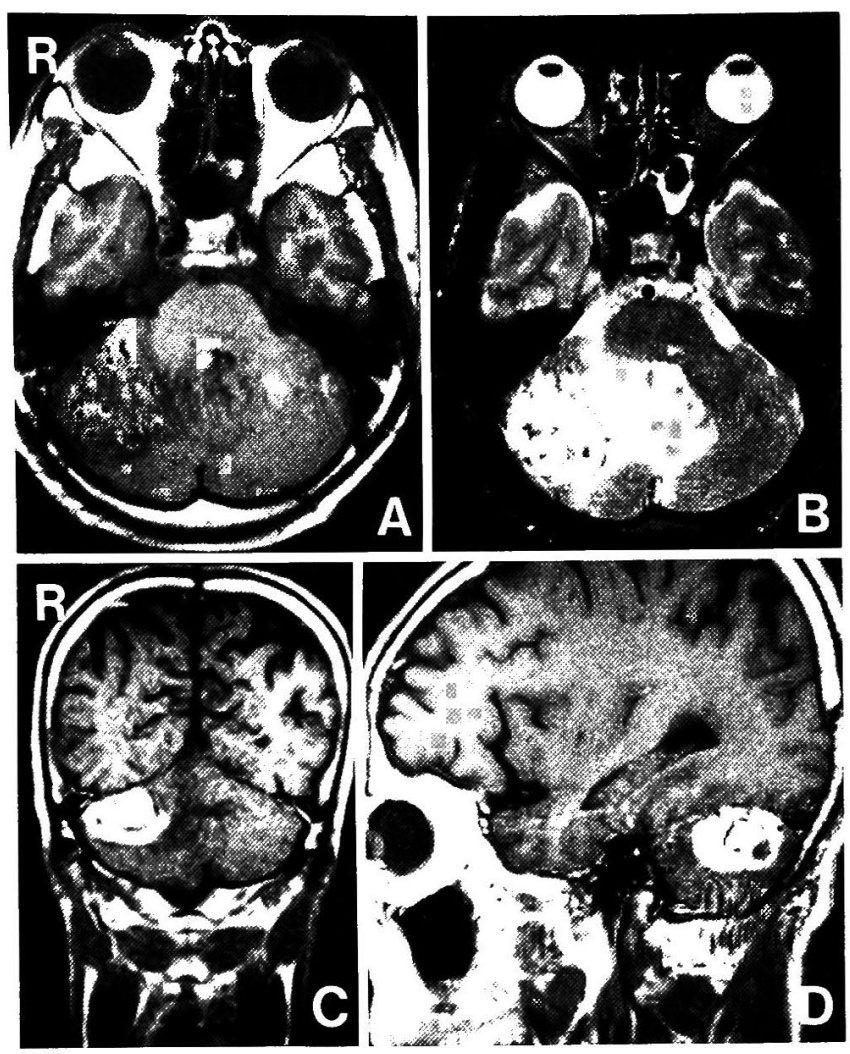

Fig. 1 A: $T_{1}$-weighted magnetic resonance (MR) image showing a tumor embedded in the right cerebellar hemisphere with multiple low intensity areas. $B: T_{2}$-weighted $M R$ image disclosing a high-intensity zone around the mass, indicating peritumoral edema. C, D: $T_{1}$-weighted $M R$ images showing the tumor abutting the tentorium and cordlike flow voids in the mass.

gadolinium administration (Fig. 1C, D). Vertebral angiography disclosed a hypervascular mass with early venous filling in the right cerebellar hemisphere (Fig. 2A, B). The main feeding arteries were the tonsillohemispheric branch of the posterior inferior cerebellar artery, the lateral branch of the anterior inferior cerebellar artery, and the anterior lateral marginal branch of the superior cerebellar artery. The tumor stain persisted in the capillary and venous phases, and drained into the superior hemispheric vein. Right external carotid angiography demonstrated tumor blush originating from the meningeal branches of the dilated occipital artery, the posterior branch of the middle meningeal artery, and the tentorial branch through the foramen spinosum (Fig. 2C). The tumor stain drained into the transverse sinus through the tentorial sinus. Right carotid angiography showed tumor stain fed from

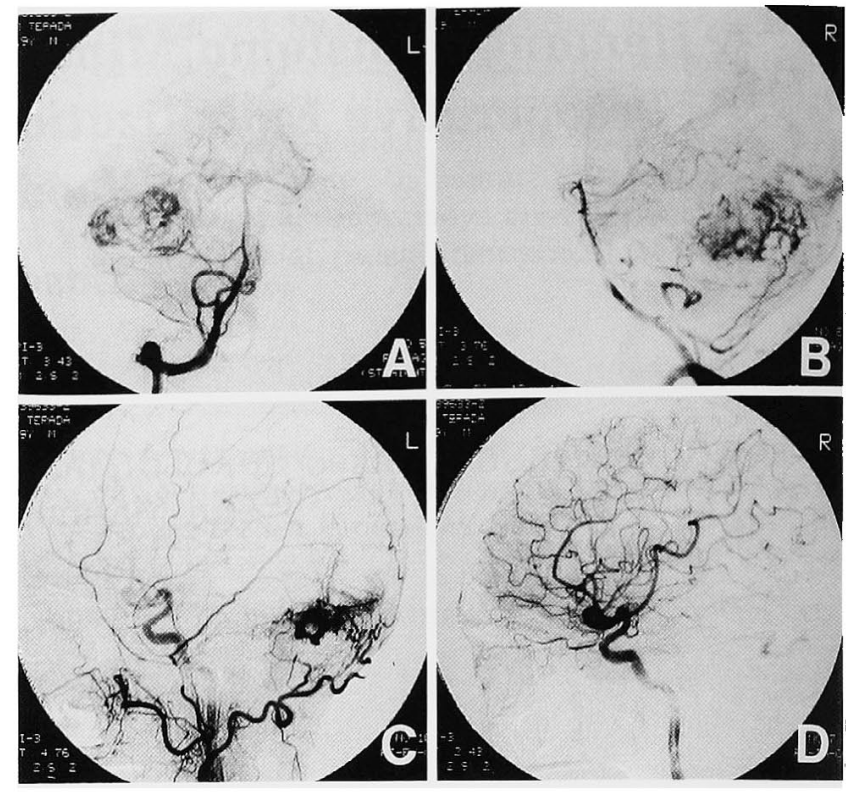

Fig. 2 A, B: Vertebral angiograms disclosing a hypervascular mass supplied from the superior cerebellar, anterior inferior cerebellar, and posterior inferior cerebellar arteries. C: External carotid angiogram showing a prominent vascular stain from the meningeal branches of the occipital artery, posterior branch of the middle meningeal artery, and the tentorial branch through the foramen spinosum. D: Internal carotid angiogram showing a faint tumor stain from the marginal tentorial artery.

the marginal tentorial artery of the dilated meningohypophyseal trunk (Fig. 2D). Because of the dural attachment and meningeal arterial blood supply to the tumor, tentorial meningioma, especially the angioblastic type, was considered in addition to hemangioblastoma in an unusual location.

Prior to surgery, embolization of the occipital artery and the posterior branch of the middle meningeal artery was performed with hydroxyethyl methacrylate-co-methyl methacrylate ${ }^{11)}$ and Spongel. Angiography showed the tumor stain from these arteries mostly disappeared. The patient underwent surgery the following day. The tumor was resected totally using a suboccipital retromastoid approach, with the patient in the left three-quarter prone position. The tumor adhered tightly to the inferior aspect of the tentorium and was nourished by many feeding arteries, i.e., the meningeal branch of occipital artery, the posterior branch of middle meningeal artery, and the marginal tentorial artery. The tumor was solid without cystic component and abutted 


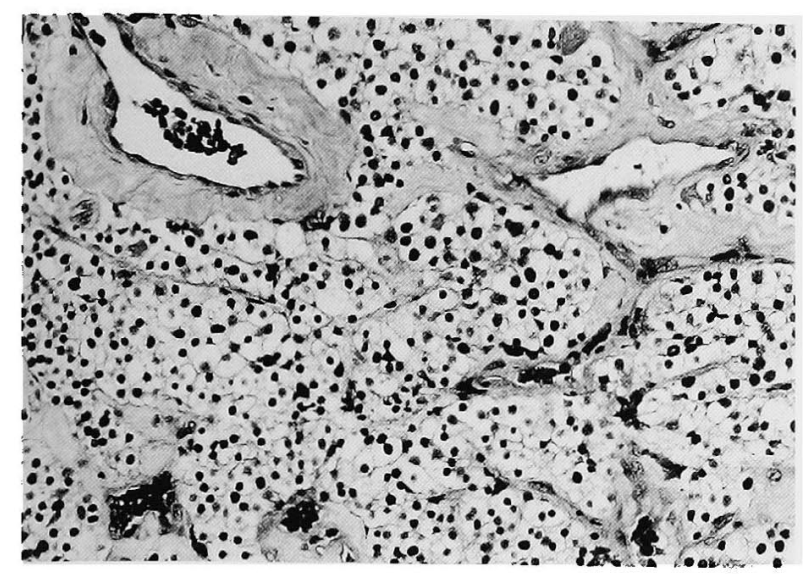

Fig. 3 Photomicrograph of the hemangioblastoma specimen showing abundant stromal cells with foamy cytoplasm and endothelial-lined vascular channels. HE stain, original magnification $\times \mathbf{5 0}$.

onto the pial surface of the right cerebellar hemisphere. Due to the preoperative embolization, bleeding could be controlled well when the tumor was resected in toto as one mass from the tentorial attachment, and blood loss was estimated $400 \mathrm{ml}$. The postoperative course was uneventful, and the patient was discharged 10 days later without additional neurological deficit.

Histological examination of the resected tumor revealed numerous endothelial-lined vascular channels and abundant stromal cells with foamy cytoplasm, consistent with hemangioblastoma (Fig. 3).

\section{Discussion}

Two previous cases of recurrent hemangioblastoma have been described with enlargement of the anterior meningeal branch of the vertebral artery and one case with enlargement of both anterior and posterior meningeal branches of the vertebral artery $^{12)}$ as well as in a patient with recurrent hemangioblastoma. ${ }^{6)}$ Primary hemangioblastomas of the cerebellum receive multiple dural arterial supplies from the meningeal branches of the occipital artery, posterior branches of the middle meningeal artery, and marginal and basal tentorial branches of the internal carotid artery. ${ }^{5}$ The enlarged tentorial artery may also be a feeding vessel. ${ }^{3-5,16-18,20)}$ However, the marginal tentorial branch is usually the contributor, and rarely the basal tentorial branch. ${ }^{17)}$ Tumor blush from the meningeal arterial supply was faint and patchy in most reported cases. In our case, the meningeal branches of the occipital artery and the marginal tentorial artery contributed to the prominent tumor blush.

Preoperative embolization is sometimes recommended to reduce excessive bleeding and facilitate tumor resection. ${ }^{8,19)}$ Successful presurgical embolization has been achieved in cases of recurrent cerebellar hemangioblastoma ${ }^{8)}$ and large spinal and cerebellar hemangioblastomas. ${ }^{19)}$ We carried out preoperative embolization for our case of a large hemangioblastoma with dural involvement, and surgical resection was then performed successfully without neurological deficit. We recommend preoperative embolization in such cases with meningeal arterial supply and/or a large and critical hemangioblastoma.

\section{References}

1) Cobb CA III, Youmans JR: Sarcomas and neoplasms of blood vessels, in Youmans JR (ed): Neurological Surgery. A Comprehensive Reference Guide to the Diagnosis and Management of Neurosurgical Problems, ed 3. Philadelphia, WB Saunders, 1990, pp 3152-3159

2) Constans JP, Meder F, Maiuri F, Donzelli R, Spaziante R, de Divitiis E: Posterior fossa hemangioblastomas. Surg Neurol 25: 269-275, 1986

3) El Gammel T, Roebuck EJ, duBoulay GH, Hoare RD: Further causes of hypertrophied tentorial arteries. $\mathrm{Br}$ J Radiol 40: 350-357, 1967

4) Handa J, Miwa Y, Shimizu Y, Handa H: Cerebellar hemangioblastoma with an enlarged tentorial arteries. Surg Neurol 2: 55-57, 1974

5) Handa J, Nakazawa T, Watanabe K, Suzuki F: Haemangioblastoma with multiple dural arterial supply. Case report. Acta Neurochir (Wien) 73: 193-199, 1984

6) Hawkins TD, Melcher DH: A meningeal artery in falx cerebelli. Clin Radiol 17: 377-383, 1966

7) Ho VB, Smirniotopoulos JG, Murphy FM, Rushing EJ: Radiologic-pathologic correlation: hemangioblastoma. AJNR Am J Neuroradiol 13: 1343-1352, 1992

8) Horton JA, Eelkema E, Albright AL: Preoperative embolization of a hemangioblastoma. Abbreviated reports. AJNR Am J Neuroradiol 10: 203, 1989

9) Hotta H, Uede T, Morimoto S, Tanabe S, Hashi K, Takeda M: Optic nerve hemangioblastoma. Case report. Neurol Med Chir (Tokyo) 29: 948-952, 1989

10) In S, Miyagi J, Kojho N, Kuramoto S, Uehara M: Intraorbital optic nerve hemangioblastoma with von Hippel-Lindau disease. J Neurosurg 56: 426-429, 1982

11) Kazekawa $K$, Iwata $H$, Shimozuru $T$, Sampei $K$, Sakaki N, Morikawa N, Matsuda S, Ikada Y: Nontoxic embolic liquids for treatment of arteriovenous malformations. J Biomed Mater Res 38: 79-86, 1997

12) Newton TH: The anterior and posterior meningeal branches of the vertebral artery. Radiology 91: 271279, 1968

13) Reynier $Y$, Baldini M, Hassoun H, Vigouroux RP, 
Paillas JE: Haemangioblastoma of the brain. Computed tomography and angiographic studies in 17 patients. Acta Neurochir (Wien) 74: 12-17, 1985

14) Sawin PD, Follett KA, Wen BC, Law ER: Symptomatic intrasellar hemangioblastoma in a child treated with subtotal resection and adjuvant radiosurgery. J Neurosurg 84: 1046-1050, 1996

15) Silver MI, Hennigar G: Cerebellar hemangioma (hemangioblastoma). A clinicopathological review of 40 cases. J Neurosurg 9: 484-492, 1952

16) Skucas J, Brinker RA: Cerebellar hemangioblastoma with a tentorial artery supply. Report of a case. Neuroradiology 3: 113-115, 1971

17) Skultety FM, Sorrell MF, Burklund CW: Hemangioblastoma of the cerebellum associated with erythrocytosis and an unusual blood supply. Case report. J Neurosurg 32: 700-705, 1970
18) Smaltino F, Granieri U: Visualizzazione di una branca tentoriale del sifone carotideo irrorante un emoangioblastoma cerebellare. Minerva Neurochir 12: 242-245, 1968

19) Tampieri D, Leblanc $R$, TerBrugge K: Preoperative embolization of brain and spinal hemangioblastomas. Neurosurgery 33: 502-505, 1993

20) Wirtala AO, Loop JW: Association of an enlarged tentorial artery with cerebellar hemangioblastoma. A case report. Radiology 96: 67-68, 1970

Address reprint requests to: H. Tsugu, M.D., Department of Neurosurgery, Fukuoka University School of Medicine, 7-45-1 Nanakuma, Jonan-ku, Fukuoka 814-0180, Japan. 